\title{
Hypotrichosis with Juvenile Macular Dystrophy in Saudi Arabia: A Case Report
}

\author{
Azhar Ahmed $^{a} \quad$ Azhar Alali $^{a}$ Osama Alsharifa, b Adnan Kaki ${ }^{a}$ \\ aDepartment of Dermatology, King Fahad General Hospital, Medina, Saudi Arabia; ${ }^{\mathrm{b}}$ Medina Maternity and Children \\ Hospital, Medina, Saudi Arabia
}

\section{Established Fact}

- Hypotrichosis with juvenile macular dystrophy (HJMD) is an autosomal recessive disorder due to a mutation in the $\mathrm{CDH} 3$ gene. As its name indicates, the disease classically presented with hypotrichosis and early visual impairment.

\section{Novel Insight}

- We emphasize the importance of genetic testing for proper genetic counseling. In the family members presented herein, we inform them that this disease is running as an autosomal recessive manner so better for the kids not to get married from their relatives. Besides, their potential partners should undergo genetic testing to exclude any heterozygous mutation in the $\mathrm{CDH} 3$ gene.

\section{Keywords}

Hypotrichosis · Genetic hair disorders · Childhood alopecia · Visual impairment · Blindness

\begin{abstract}
Hypotrichosis with juvenile macular dystrophy is an autosomal recessive disorder due to a mutation in the $\mathrm{CDH} 3$ gene. As its name indicates, the disease classically presented with hypotrichosis and early visual impairment. We describe herein a family member with alopecia since birth associated with severe visual impairment in their early life. We suspect the diagnosis of hypotrichosis with juvenile macular dystrophy. Genetic testing confirms the clinical suspension. We emphasize the importance of genetic testing for proper genetic counseling.

(c) 2020 S. Karger AG, Basel
\end{abstract}

\section{Introduction}

Hypotrichosis with juvenile macular dystrophy (HJMD) (MIM ID \#601553) is a rare genetic hair disorder that manifests with hypotrichosis and childhood visual impairment leading to early blindness [1]. This condition is an autosomal recessive disorder with approximately 50 cases reported worldwide. It showed a mutation in $\mathrm{CDH} 3$ on 16q22.1 chromosome which encodes $\mathrm{P}$-cadherin, which is expressed in the hair follicle and retinal pigment epithelium [2].

\section{Case Report}

A forty-year-old male born from consanguineous healthy parents presented to the dermatology clinic with diffuse short sparse hair over his scalp since birth, and he never had his hair longer than

karger@karger.com
www.karger.com/sad
Karger



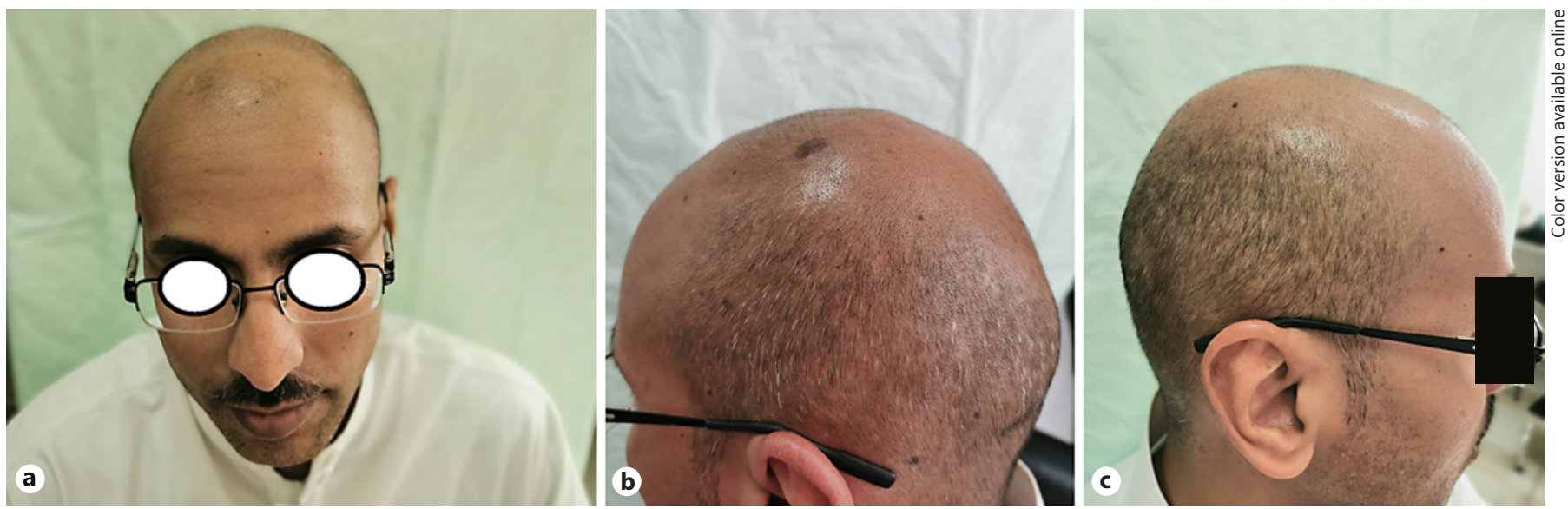

Fig. 1. a Diffuse short sparse hair over the patient's scalp. Note the normal eyebrows and beard area. b Occipital and lateral view. c Short sparse hair on the lateral view.

Fig. 2. a Eighteen-month-old baby boy with diffuse short hair over his scalp. b Vertex view.
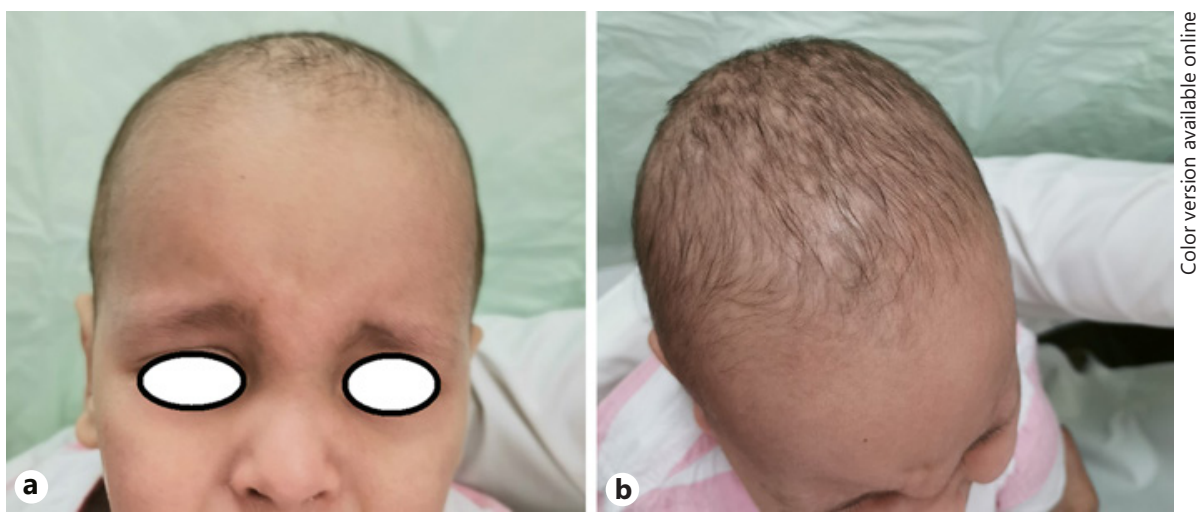

Fig. 3. a Seven-month-old baby girl with diffuse short hair. b Vertex view.
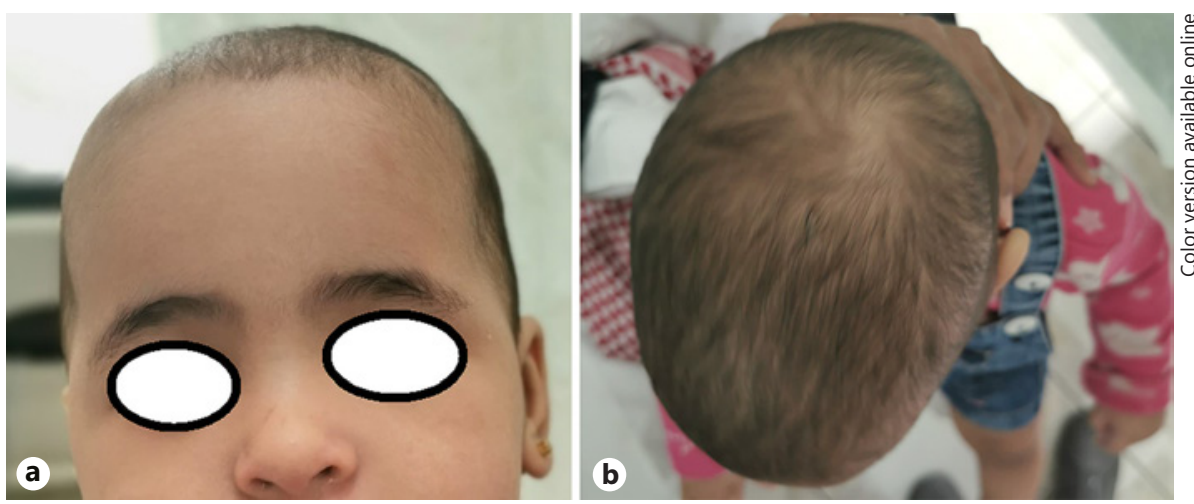

his current presentation (Fig. 1). Upon asking him about the other body hair, he stated it was normally growing.

The patient was asked about any associated comorbidities like hearing loss or a visual impairment, he mentioned a history of macular degeneration in both eyes that was discovered since his early childhood and gradually progressed to blindness in his early 20s. The patient has an 18-month-old baby boy with sparse short hair since birth (Fig. 2 and a 7-month-old baby girl with the same hair presentation (Fig. 3). Upon eye checkup, there was diffuse retinal pigment epithelium hypertrophy.

The patient is a member of eleven siblings in total with 1 affected sister (Fig. 4) and 2 affected brothers. They have the same clinical hair manifestation since birth with the same retinal involvement.

On examination, the patient looks in good mental and physical health. Scalp examination showed Hamilton stage VII of male pat- 

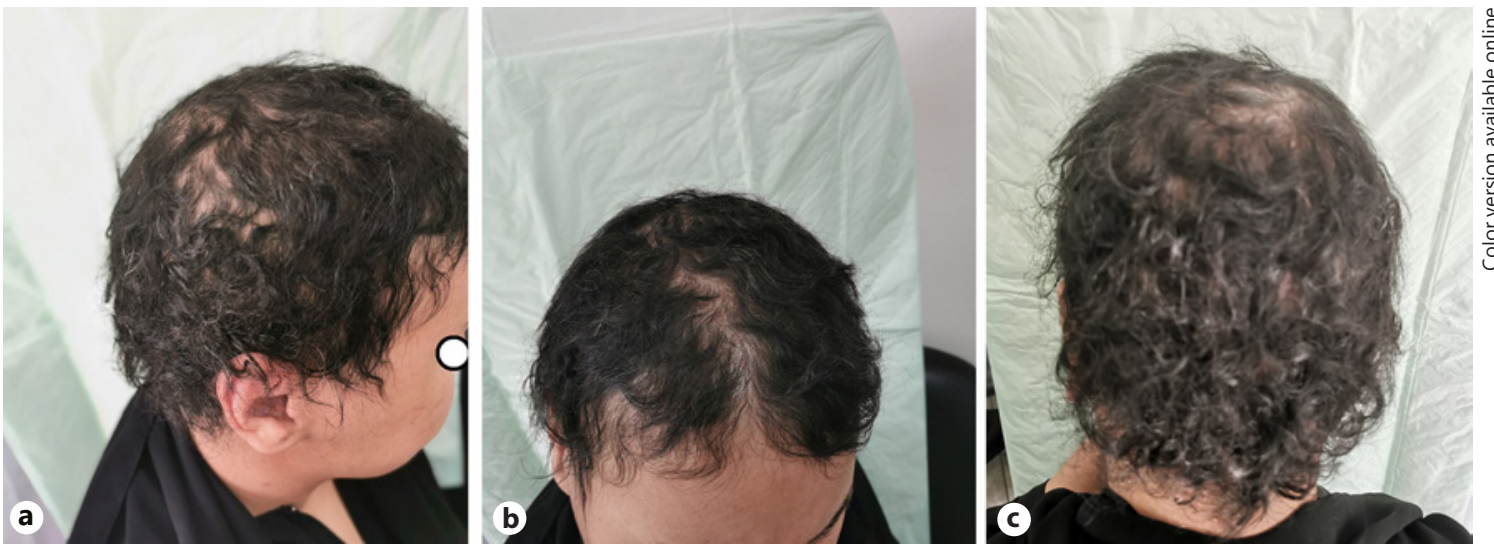

Fig. 4. a The patient's sister with patchy alopecia and hypotrichosis over her scalp. b Patient's sister with diffuse sparse hair on her vertex area. c Occipital view of scalp hair.

Fig. 5. Trichoscopic examination showed low hair density with fine short hair some with a blunt end (black arrow) and few with a tapered end (green arrow) secondary to shaving.

Fig. 6. The patient pedigree.

5

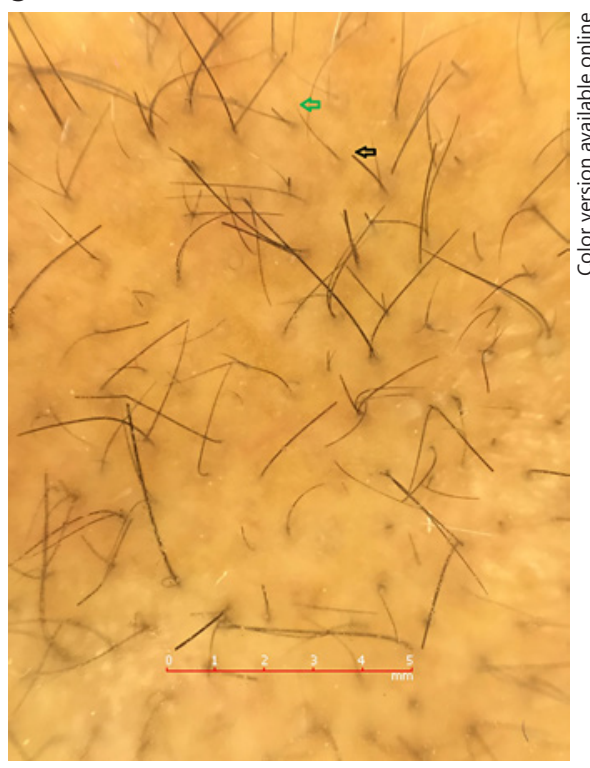

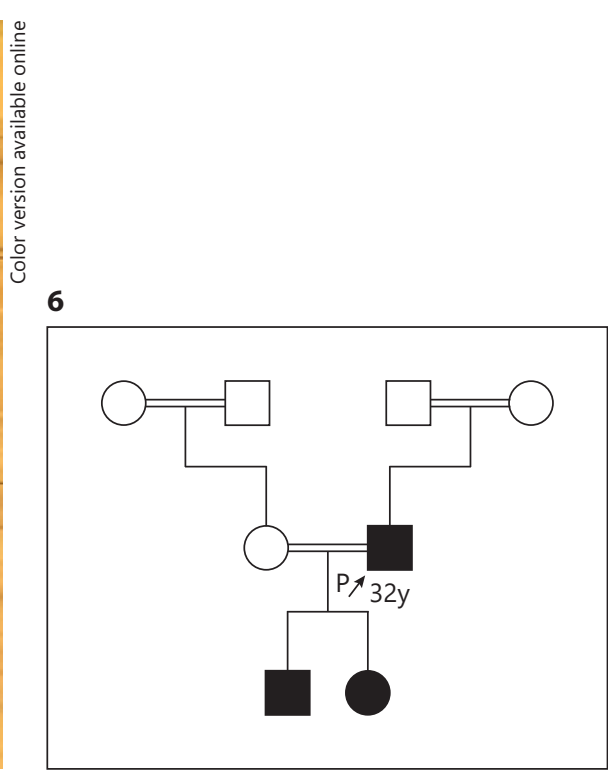

tern hair loss associated with diffuse short sparse hair exclusively over his scalp and low overall density, and gentle hair pulling test was positive for telogen hair. Eyebrows and eyelashes, beard, and pubic and body hair are preserved. Skin, teeth, nails, sweat glands, and hand examination were not significant. Trichoscopic examination of the occipital hair had nonspecific features; it showed short thin hair (Fig. 5).

Detailed ophthalmological examination including the fundus exam and optical coherent tomography revealed that the patient is legally blind with a vision of 20/400 on both eyes (legally blind refers to a person who is blind without his eyeglass or contact lenses assistance. A person is considered legally blind if he/she has central visual acuity of 20/200 or worse in the better-seeing eye with best correction (using glasses or contact lenses) at a distance or if he/ she has visual field restriction where the widest diameter is $20^{\circ}$ or less in the better-seeing eye [3]. The fundus exam showed diffuse chorioretinal atrophy with lamellar macular hole, retinoschisis, and loss of outer retina documented on optical coherent tomography.

Clinical findings suggested the diagnosis of HJMD. A wholeexome sequencing study was done and showed homozygous stop gain mutation c.C307T(p.Arg103Ter) at exon 4 (NM_001793) of the $\mathrm{CDH} 3$ gene.

Another incidental/secondary sequence variant was detected and showed a homozygous missense mutation c.G485A(p.Arg$162 \mathrm{Gln}$ ) at exon 6 of ARL2BP and another heterozygous missense mutation c.G314A(p.Arg105Gln) at exon 2 of the TEK gene. The patient's pedigree is shown in (Fig. 6). 


\section{Discussion}

HJMD has been first described in 1935, in which the patient presents with short sparse hair since birth followed by decreased visual acuity secondary to progressive macular degeneration leading to blindness between the second and fourth decade of life. Symptoms' severity varies from patient to patient, but they all manifest with both retinal degeneration and short sparse scalp hair since birth [4]. The diagnosis of this disorder is based on both hair hypotrichosis and degenerative and pigmentary abnormalities of the fovea on fundoscopy [5]. This disorder usually affects the scalp hair, but it may affect the eyebrows and eyelashes $[6,7]$ with the preservation of other body hair [6]. Light microscopy and scanning electron microscopy of the hair shaft can be normal or may show hair shaft abnormalities in the form of pili torti [6]. Bergman et al. [8] had scalp biopsy from $6 \mathrm{HJMD}$ patients and conclude that the most common abnormalities in HJMD were chronic telogen effluvium where the reading in 5 patients showed more catagen-telogen hair follicles, and an increased ratio of vellus to terminal hair follicles was noted in 2 patients.

This autosomal recessive disorder is due to pathogenic variants in the $\mathrm{CDH} 3$ gene, which encodes $\mathrm{P}$-cadherin and is responsible for calcium-dependent cell to cell adhesion. Other mutations in the $\mathrm{CDH} 3$ gene may also cause another autosomal recessive ectodermal dysplasia, ectrodactyly, and macular dystrophy (EEM; OMIM \#225280). This syndrome manifests with hypotrichosis, macular dystrophy, and limb defects like ectrodactyly, syndactyly, and camptodactyly [9].

The retinal part of this syndrome has been reassessed. It is now known to have eye involvement at an earlier age of onset rather than juvenile stated on its name [4]. Moreover, researches showed a wider involvement of the retina exceeding beyond the macular involvement [10].

\section{Conclusion}

Although the acquired form of alopecia is the most common presentation in any patient presented with alopecia since his/her early life, we should consider the differential diagnosis of genetic hair abnormalities in any patient with this presentation. We emphasize the importance of genetic testing for proper genetic counseling. In the family members presented herein, we inform them that this disease is running as an autosomal recessive manner so better for the kids not to get married from their relatives. Besides, their potential partners should undergo genetic testing to exclude any heterozygous mutation in the $\mathrm{CDH} 3$ gene.

\section{Acknowledgements}

We gratefully acknowledge the family members involved in this study.

\section{Statement of Ethics}

All procedures followed were in accordance with the ethical standards of the responsible committee on human experimentation (institutional and national) and with the Helsinki Declaration of 1964, as revised in 2013. The adult patients and the children's parents have given their written informed consent to publish the case and images.

\section{Conflict of Interest Statement}

The authors have nothing to declare.

\section{Funding Sources}

No funding or sponsorship was received for this article.

\section{References}

1 Singh MS, Broadgate S, Mathur R, Holt R, Halford S, MacLaren RE. Hypotrichosis and juvenile macular dystrophy caused by $\mathrm{CDH} 3$ mutation: a candidate disease for retinal gene therapy. Sci Rep. 2016;6:23674.

2 Vicente LP, Finzi S, Susanna R, Young TL. Hypotrichosis with juvenile macular dystrophy: a case report with molecular study. Arq Bras Oftalmol. 2017;80(1):49-51.
3 Chakravarthy U, Bailey CC, Johnston RL, McKibbin M, Khan RS, Mahmood S, et al. Characterizing disease burden and progression of geographic atrophy secondary to agerelated macular degeneration. Ophthalmology. 2018 Jun;125(6):842-9.

4 Indelman M, Hamel CP, Bergman R, Nischal KK, Thompson D, Surget MO, et al. Phenotypic diversity and mutation spectrum in hypotrichosis with juvenile macular dystrophy. J Invest Dermatol. 2003;121(5):1217-20.
5 Almeida FT, Carneiro-Freitas R, Caldas R, Vieira AP. Hypotrichosis with juvenile macular dystrophy. Int J Trichology. 2018;10(5): 234-6.

6 Indelman M, Bergman R, Lurie R, Richard G, Miller B, Petronius D, et al. A missense mutation in $\mathrm{CDH} 3$, encoding P-cadherin, causes hypotrichosis with juvenile macular dystrophy. J Invest Dermatol. 2002;119(5):1210-3. 
7 Indelman $\mathrm{M}$, Eason J, Hummel M, Loza O, Suri M, Leys MJ, et al. Novel CDH3 mutations in hypotrichosis with juvenile macular dystrophy. Clin Exp Dermatol. 2007;32(2): 191-6.

8 Bergman R, Sapir M, Sprecher E. Histopathology of hypotrichosis with juvenile macular dystrophy. Am J Dermatopathol. 2004; 26(3):205-9.
9 Nasser F, Mulahasanovic L, Alkhateeb M, Biskup S, Stingl K, Zrenner E. Hypotrichosis with cone-rod dystrophy in a patient with cadherin 3 (CDH3) mutation. Doc Ophthalmol. 2019;138(2):153-60.
10 Blanco-Kelly F, Rodrigues-Jacy da Silva L, Sanchez-Navarro I, Riveiro-Alvarez R, Lopez-Martinez MA, Corton M, et al. New $\mathrm{CDH} 3$ mutation in the first Spanish case of hypotrichosis with juvenile macular dystrophy, a case report. BMC Med Genet. 2017; 18(1):1. 